\title{
Anonimitas di Media Sosial: Sarana Kebebasan Berekspresi atau Patologi Demokrasi?
}

\author{
Nurul Hasfi, Sunyoto Usmand dan Hedi Pudjo Santosa \\ Program Studi Ilmu Komunikasi, FISIP, Undip, Semarang \\ J1. Prof Soedharto, Tembalang, Semarang Telp.024.7465408 \\ Email: uul58@yahoo.com
}

\begin{abstract}
Anonymity is crucial medium of democracy that is used for guaranting freedom of expressing freely without fear. The study was conducted to identify the role of anonym Twitter account that taking part in the political communication process during 2014 Indonesian presidential election. By applying Critical Discourse Analysis (CDA) this study identified texts produced by anonym Twitter accounst discussing about precidential candidate figure and explore their roles in the political communication. The results of the study reflect that anonym Twitter accounts do not support freedom of expression but contrary it is involved in elite political contestation. Political debates among anonym Twitter accounts create pathology of democracy degradates democratization process in social media.
\end{abstract}

Keywords: anonimity, Twitter, Digital Democracy, Patology of Democracy

\begin{abstract}
Abstrak
Anonimitas merupakan bagian penting dalam demokrasi sebagai sarana untuk mengemukakan pendapat tanpa rasa takut. Studi ini mengidentifikasi peran akun anonim di media sosial dalam proses diskusi politik pada pemilu presiden

2014. Dengan metode analisis wacana kritis studi ini mengidentifikasi teks-teks yang diproduksi akunakun Twitter anonim dalam mendiskusikan sosok calon presiden 2014 serta mengidentifikasi peran mereka dalam proses demokrasi politik. Analisis teks memperlihatkan akun anonim tidak berperan dalam mendukung kebebasan berekspresi publik namun sebaliknya justru menjadi alat kekuasaan elite. Debat politik antar akun anonim justru manjadi patologi yang mendegradasi proses demokrasi di media sosial.
\end{abstract}

Kata Kunci: anonimitas, Twitter, demokrasi digital, patologi Demokrasi

\section{Pendahuluan}

Meski belum ada pengaturan tentang anonimitas di Indonesia, perkembangan teknologi internet yang pesat di Indonesia sejak awal tahun 2000-an telah menjadi ruang tumbuhnya fenomena anonimitas dalam berbagai medium mulai dari web, blog, email hingga situs terpopuler yakni media sosial. Diakui, anonimitas di media sosial menjadi fenomena unik dalam praktik demokrasi di Indonesia. Disatu sisi keberadaan mereka telah menjamin kebebasan berekspresi bagi masyarakat Indonesia, namun disisi lain memunculkan permasalahan terutama problematika transparansi dan akuntabilitas infomasi yang mereka bawa.

Anonimitas berasal dari kata Yunani 
yang berarti 'tanpa nama' yang dipakai untuk mengidentifikasi obyek baik berupa manusia ataupun benda (Chawki, 2008: 1). Di negara demokrasi terbesar di dunia Amerika, anonimitas dijamin First Amendment yang mengatur kebebasan berpendapat disana. Akdeniz (2002, 230) yang meneliti anonimitas, demokrasi dan ruang siber juga menyebut bahwa European Court of Human Rights (ECHR) menegaskan anonimitas merupakan fasilitator kebebasan berekspresi. Dari sudut pandang tersebut bisa dikatakan bahwa anonimitas merupakan bagian yang tidak terpisahkan dalam praktik menyampaikan pendapat dengan bebas.

Dalam konteks anonimitas di dunia maya, Pavlíček $(2005,10)$ membagi anonimitas dalam berbagai level. Semakin mudah pihak luar menjangkau identitas akun maka level anonimitas semakin rendah. Logikanya semakun mudah menjangkau identitas akun anonim maka proses verifikasi kebenaran atas informasi yang disampaikan semakin terbuka. Merujuk pada pendapat Pavlíček tersebut, penelitian ini menggolongkan akun Twitter anonim yang menjadi sampel penelitian ini sabagai pseudonym (pseudo anonym). Dalam anonimitas di internet pseudonym memiliki nama permanen yang dilindungi dengan password. Pihak luar juga dapat mengakses IP address komputer yang dipakainya sehingga keberadaannya dapat terlacak. Pseudonym berbeda dengan fully anonymous status misalnya yang memblokir IP address - nya sehingga tidak memungkinkan pihak luar melacak keberadaannya. Pseudonym juga berbeda dengan level anonimitas yang disebut identity status yang menyediakan identitas seperti nomor telepon, alamat rumah atau kantor yang memungkinkan pihak luar melacaknya di dunia nyata. Akun anonim di media sosial yang menjadi obyek penelitian tidak menyediakan ruang konfirmasi yang memadahi, karena diskusi hanya sebaras dilakukan di media sosial saja.

Berbagai penelitian tentang anonimitas telah banyak dilakukan. Chawki (2006:7) yang berfokus pada penggunaan anonimitas untuk diskusi online tentang korban kekerasan seksual, isu minoritas dan korban perang. Ia menyoroti anonimitas yang memfasilitasi warga korban kekerasan melaporkan tindak kekerasan yang dialaminya melalui email yang mampu menghilangkan jejak identitas pengirim. Sementara Akdeniz (2002, 227) berfokus pada anonimitas yang difasilitasi oleh sebuah institusi bernama Hush Communication \& Cyber Liberties. Website yang dibuat menyediakan ruang bagi korban perang untuk melaporkan kejahatan perang atau warga di negara represif yang melaporkan pelanggaran HAM tanpa diketahui identitasnya. Sementara Zajácz (2013, 1) membahas anonimitas dengan berfokus pada kasus konflik antara WikiLeaks dengan pemerintah US terkait kebocoran setengah juta dokumen rahasia kebijakan militer dan diplomasi pemerintah US melalui WikiLeaks. Zajácz menegaskan kasus WikiLeaks vs pemerintah US menjadi isu yang semakin memperkuat posisi pro anonimitas - melihat anonimitas sebagai alat penting bagi pengkritik (wistleblower) dalam demokrasi - sekaligus memperuncing konflik dengan mereka yang berpendapat bahwa produk anonimitas kurang akuntabel (lack of accountability).

Berbagai studi tentang anonimitas di berbagai konteks diatas, mendorong peneliti untuk melihat peran anonimitas dalam konteks politik di Indonesia dengan berfokus pada aktivitas akun Twitter anonim pada perdebatan politik pemilu presiden 2014. Benarkah akunakun anonim dalam konteks diskusi politik di Indonesia ini juga membawa pesan demokrasi bagi publik Indonesia. Peneliti mengindentifikasi sebuah permasalahan yang muncul akhir-akhir ini terutama adanya indikasi keterlibatan akunakun Twitter anonim dalam kontestasi politik di tingkat elite dan keterlibatan mereka dalam memproduksi wacana-wacana sensitif SARA yang membahayakan persatuan dan kesatuan bangsa.

Penelitian ini juga diharapkan menyumbangkan diskusi tentang perdebatan politik online dalam konteks pemilu presiden 
2014. Salah satu penelitian terkait dengan anonimitas dalam konteks pemilu. Salah satu penelitian tentang pemilu presiden 2014 yang memiliki kedekatan dengan penelitian yakni yang dilakukan oleh Wadipalapa (2015) yang membahas kontestasi pesan politik dalam media melalui teks berupa meme yang menyembunyikan praktik-praktik kekuasaan.

Dalam konteks perhelatan politik seperti pilpres, nampaknya peran media sosial tidak lagi mendorong demokrasi sebagaimana gerakan online 'Koin untuk Prita' dan Cicak vs Buaya (Marlyna, 2013:1; Gazali, 2014: 433) atau gerakan sosial \#SaveSatinah di Twitter (Sari, 2015). Berangkat dari permasalahan tersebut, artikel ini ingin mendapatkan gambaran komprehensip tentang peran anonimitas di media sosial dalam proses demokrasi di Indonesia. Untuk bisa mengidentifikasi peran akun Twitter anonim dalam perdebatan politik tersebut, maka penelitian ini melakukan analisis wacana kritis terhadap teks-teks yang mereka produksi selama pemilu presiden 2014. Analisis terhadap teks tersebut diharapkan mampu a) menggambarkan isu dominan yang diperdebatkan para akun anonim ini; b) Bagaimana isu dominan yang dimaksud merepresentasi Jokowi dan Prabowo; c) praktik kekuasaan yang melatar-belakangi aktivitas produksi wacana capres oleh akun Twitter Anonim; d) peran akun Twitter anonim dalam proses demokrasi

\section{Metode Penelitian}

Penelitian ini merupakan penelitian kualitatif dengan metode utama analisis wacana kritis atau Critical Discourse Analysis (CDA) yang dikembangkan oleh Fairclough (1989, 1992, 1995). Ada tiga 3 dimensi kerangka kerja CDA Fairclough (1992, 73-91) yang diterapkan dalam penelitian ini untuk menjawab pertanyaan penelitian, yakni; 1) text analysis; 2) discourse practice; dan 3) sociocultural practice. Peneliti memfokuskan analisis teks untuk menjawab pertanyaan tentang isu dominan yang terbangun dan representasi Jokowi dan Prabowo yang terbentuk. Analisis praktik diskursif (discourse practice) merupakan analisis terhadap produksi, konsumsi dan distribusi wacana yang dibangun akun Twitter anonim. Analisis ini membantu peneliti mengidentifikasi pola diskusi politik yang dilakukan akun Twitter anonim. Sementara pada analisis sosio-kultural (socio-cultural) secara khusus dipakai untuk mengidentifikasi praktik kekuasaan yang tersembunyi dibalik representasi calon presiden.

Data penelitian ini meliputi teks (interaksi pembicaraan, grafis, meme, karikatur, foto) yang diproduksi tiga akun anonim @PartaiSocmed, @pkspiyungan dan@TrioMacan2000 1,5 bulan sebelum pemilu presiden 2014 . Ketiga akun Twitter anonim ini dipilih berdasarkan dua pertimbangan; a) ketiganya memiliki pengikut (follower) tinggi yang analoginya pesan yang mereka buat efektif dikonsumsi netizen dan berdampak pada proses diskusi politik di Twitter; b) mereka aktif dalam memproduksi wacana calon presiden 2014 dan terlibat dalam diskusi politik mengenai hal tersebut.

Tabel 1 Deksripsi Akun Anonim dalam Pilpres 2014

\begin{tabular}{|l|l|l|l|}
\hline & @PartaiSocmed & @TrioMacan2000 & @pkspiyungan \\
\hline Waktu Berdiri & Oktober 2012 & April 2012 & November 2010 \\
\hline Pengikut (Follower) & $\begin{array}{l}\text { Mei: 42.929 } \\
\text { Juli: 67.234 }\end{array}$ & $\begin{array}{l}\text { Mei: 788.468 } \\
\text { Juni: 809.301 }\end{array}$ & $\begin{array}{l}\text { Mei: } 55.882 \\
\text { Juli: 66.722 }\end{array}$ \\
\hline \multirow{2}{*}{$\begin{array}{l}\text { Status saat ini } \\
(2017)\end{array}$} & Aktif & $\begin{array}{l}\text { Twitter. Kemudian berganti nama @ } \\
\text { TM2000Back dan @TheRoninWar } \\
\text { namun ber-follower rendah }\end{array}$ & $\begin{array}{l}\text { Aktif namun } \\
\text { berganti } \\
\text { nama akun @ } \\
\text { maspiyungan }\end{array}$ \\
\hline
\end{tabular}


Hasil dan Pembahasan

Kontestasi Wacana Calon Presiden oleh Akun Twitter Anonim

Analisis teks akun Twitter anonim merefleksikan setidaknya delapan isu yang dibangun oleh akun Twitter anonim terkait dengan calon presiden 2014 dalam usaha merepresentasikan kedua kandidat (Tabel 2). Identifikasi isu dan representasi yang terbentuk ini sekaligus merefleksikan keberpihakan politik mereka. Akun@partaisocmed teridentifikasi membawa wacana yang mendukung pencalonan Jokowi, sementara akun @TrioMacan2000 dan @pkspiyungan teridentifikasi memiliki posisi politik mendukung Prabowo.

Pertama, isu dukungan kelompok agama, kontestasi akun Twitter anonim berfokus usaha penggunaan kelompok agama mayoritas yakni Islam untuk membangun representasi calon presiden ideal dan menggunakan kelompok agama minoritas untuk membangun representasi calon presiden tidak ideal. Alat yang dipakai untuk merepresentasikan capres ideal yakni dukungan Islam. Bagian ini memunculkan oposisi biner (binner oposition) dimana pihak Jokowi direpresentasikan mendapat dukungan Islam tradisional yang diwakili oleh dukungan PKB yang membawa simbol Nahdlatul Ulama (NU), bersaing dengan representasi ideologi Islam modernis yang melekat ormas Islam Muhammadiyah yang dalam konteks pemilu presiden 2014 lebih dekat dengan empat partai

Tabel 2. Isu dan Representasi Jokowi dan Prabowo oleh Akun Twitter Anonim

\begin{tabular}{|c|c|c|c|c|}
\hline No & Isu Dominan & (a)Partaisocmed & @pkspiyungan & (a)TrioMacan2000 \\
\hline 1 & $\begin{array}{l}\text { Dukungan } \\
\text { kelompok agama }\end{array}$ & $\begin{array}{l}\text { Jokowi didukung } \\
\text { Islam Moderat/ } \\
\text { Tradisional }\end{array}$ & $\begin{array}{l}\text { Prabowo didukung } \\
\text { Islam Modern }\end{array}$ & $\begin{array}{l}\text { Jokowi didukung } \\
\text { Katolik, Kristen, } \\
\text { Syiah, Ahmadiyah, } \\
\text { JIL }\end{array}$ \\
\hline 2 & Identitas & $\begin{array}{l}\text { Jokowi Jawa- } \\
\text { Muslim } \\
\text { Jokowi Sholat, } \\
\text { menjadi Imam } \\
\text { sholat, Umroh, } \\
\text { bergelar Haji }\end{array}$ & $\begin{array}{l}\text { Jokowi Katolik, } \\
\text { Kejawen } \\
\text { tak bisa Sholat dan } \\
\text { Wudlu, } \\
\text { Jokowi Cina-Katolik. } \\
\text { Prabowo Muslim. }\end{array}$ & $\begin{array}{l}\text { Jokowi Katolik, } \\
\text { Jokowi Kejawen } \\
\text { Jokowi tak bisa } \\
\text { Sholat dan Wudlu } \\
\text { Jokowi Cina-Katolik }\end{array}$ \\
\hline 3 & HAM & $\begin{array}{l}\text { Prabowo melanggar } \\
\text { HAM }\end{array}$ & $\begin{array}{l}\text { Prabowo Tidak } \\
\text { Melanggar HAM }\end{array}$ & $\begin{array}{l}\text { Prabowo tidak } \\
\text { melanggar HAM, } \\
\text { Prabowo Jendral } \\
\text { vang terbuang }\end{array}$ \\
\hline 4 & Korupsi & $\begin{array}{l}\text { Prabowo korupsi, } \\
\text { Jokowi anti korupsi. }\end{array}$ & $\begin{array}{l}\text { Jokowi Korupsi, } \\
\text { Jokowi berpolitik } \\
\text { transaksional }\end{array}$ & $\begin{array}{l}\text { Revolusi mental } \\
\text { gagal, Jokowi } \\
\text { korupsi saat jadi } \\
\text { walikota, Jokowi } \\
\text { Korupsi bus Trans } \\
\text { Jakarta. }\end{array}$ \\
\hline 5 & $\begin{array}{l}\text { Kepemimpinan } \\
\text { (Leadeship) }\end{array}$ & $\begin{array}{l}\text { Prabowo penerus } \\
\text { Orba, Prabowo } \\
\text { boneka asing, } \\
\text { Prabowo ditolak } \\
\text { asing }\end{array}$ & $\begin{array}{l}\text { Prabowo Tegas, } \\
\text { decision maker }\end{array}$ & $\begin{array}{l}\text { Jokowi Boneka: } \\
\text { Boneka Asing, } \\
\text { Boneka Militer } \\
\text { Prabowo disegani } \\
\text { Asing }\end{array}$ \\
\hline
\end{tabular}




\begin{tabular}{|c|c|c|c|c|}
\hline 6 & $\begin{array}{l}\text { Ideologi: } \\
\text { Zionis, Fasisme, } \\
\text { Komunis, } \\
\text { orde baru dan } \\
\text { Nasionalisme }\end{array}$ & $\begin{array}{l}\text { Pendukung Prabowo } \\
\text { Komunis } \\
\text { Zionis Israel* } \\
\text { Prabowo Fasisme, } \\
\text { Prabowo pengagum } \\
\text { Hitler, Prabowo } \\
\text { penerus rezin orba }\end{array}$ & $\begin{array}{l}\text { Pendukung Jokowi } \\
\text { PKI: anarkis, dan } \\
\text { rencana penghapusan } \\
\text { kolom agama di KTP } \\
\text { Prabowo Nasionalis: } \\
\text { penerus Soekarno, } \\
\text { bukan anthek asing, } \\
\text { macan asia }\end{array}$ & $\begin{array}{l}\text { Jokowi Komunis: } \\
\text { Ayah Jokowi PKI }\end{array}$ \\
\hline 7 & SDA & $\begin{array}{l}\text { Prabowo didukung } \\
\text { mafia migas }\end{array}$ & 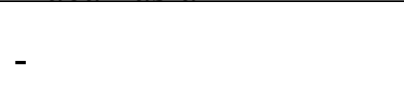 & $\begin{array}{l}\text { Jokowi didukung } \\
\text { cukong Cina }\end{array}$ \\
\hline 8 & Tampilan Fisik & $\begin{array}{l}\text { Jokowi mirip Jendral } \\
\text { Soedirman } \\
\text { Prabowo seperti } \\
\text { diktaktor Idi Amin }\end{array}$ & $\begin{array}{l}\text { Prabowo jantan, } \\
\text { ganteng, tegab dan } \\
\text { kekar } \\
\text { Jokowi klemar-klemer }\end{array}$ & $\begin{array}{l}\text { Prabowo gagah } \\
\text { Jokowi epilepsi, } \\
\text { badut jongos,klemer, } \\
\text { kurang gizi }\end{array}$ \\
\hline & \multicolumn{4}{|c|}{ Sumber: Teks Twitter 1 Mei - 9 Juli 2014} \\
\hline
\end{tabular}

Islam pendukung Prabowo yakni PAN, PKS, PPP dan PBB. Representasi dengan alat legitimasi dukungan kelompok agama ini cukup intens berlangsung di Twitter sehingga memunculkan nuansa politik Islam dan politik aliran.

Selanjutnya, dalam melemahkan kekuatan lawan, akun anonim menggunakan alat berupa identitas kelompok agama minoritas dimana pihak Jokowi direpresentasikan sebagai sosok yang didukung Katolik/ Kristen yang dilegitimasi dengan foto-toro kedekatan Jokowi dengan konglomerat beragama Katolik. Selain itu, Jokowi juga direpresentasikan didukung kelompok minoritas berbasis keagamaan lainnya seperti Syiah, Ahmadiyah dan Jamaah Islam Liberal. Serangan akun anonim Prabowo terhadap Jokowi tersebut di-counter akun@PartaiSocmed dengan merepresentasikan Prabowo didukung kelompok Islam fundamentalis Front Pembela Islam (FPI) yang dalam konteks Indonesia juga merupakan kelompok minoritas agama yang belum diterima mayoritas masyarakat muslim Indonesia.

Kedua, perdebatan wacana akun anonim juga menggunakan isu identitas yang merepresentasikan capres ideal dengan identitas
Muslim-Jawa, sementara capres tidak ideal diidentifikasi sebagai sosok Cina-Katolik. Dalam melegitimasi identitas Islam, baik akun pendukung Jokowi maupun Prabowo sama-sama menggunakan kriteria berupa kemampuan masing-masing calon presiden dalam menjalankan ritual Islam seperti sholat, wudlu, berpuasa, shalat Jumat, umroh dan naik haji. Jokowi mendapatkan serangan cukup keras berupa representasi capres Cina-KatolikKejawen. Wacana negatif terhadap Jokowi tersebut di-counter dengan wacana Jokowi Islam yang ditunjukkan dengan teks (foto-foto) yang memperlihatkan Jokowi sedang menjalankan ibadah seperti menjadi imam sholat, sholat Jumat, umroh dan naik haji. Sementara, Prabowo tidak banyak diserang dengan cara tersebut karena kuatnya representasi Islam padanya yang dilekatkan oleh dukungan mayoritas partai Islam.

Konstruksi identitas calon presiden ideal seorang Moslem-Jawa tidak muncul begitu saja. Identitas tersebut telah menjadi konstruksi lama kepemimpinan politik di Indonesia. Berbagai penelitian terdahulu yang dilakukan dari perspektif non-teks mengemukanan bahwa presiden yang diinginkan masyarakat Indonesia 
merupakan mereka yang ber-ethnis Jawa (Irawanto, Philip \& Ryan, 2011; Syamsudin, 1993; Freeland, 2007); beragama Islam (Syamsudin, 1993).

Ketiga, isu pelanggaran Hak Asasi Manusia (HAM) tidak muncul secara tibatiba namun dilatar belakangi oleh sejarah pelanggaran HAM yang dialami oleh Prabowo di masa lalu. Sebagaimana kita ketahui, Prabowo menjadi aktor yang disebut terlibat dalam penculikan dan pembunuhan aktivis 98. Dalam kontestasi menggunakan isu HAM ini, capres ideal direpresentasikan sebagai capres yang bersih dari pelanggaran HAM, sebaliknya capres tidak ideal direpresentasikan sebagai sosok yang pernah terlibat dalam pelanggaran HAM. Akun anonim pendukung Jokowi@PartaiSocmed keras merepresentasikan wacana Prabowo pelanggar HAM yang disaingi dengan wacana sebaliknya oleh akun pendukung Prabowo yakni 'Prabowo bukan pelanggar HAM'. Akun anonim pro Prabowo juga mencoba meng-counter wacana pelanggaran HAM yang menyerangnya dengan mengkonstruksi wacana Jokowi didukung jendral pelanggar HAM, serta membangun apoligi dengan merepresentasikan Prabowo sebagai korban fitnah para Jendral dan Prabowo sebagai jendral yang terbuang.

Keempat, isu korupsi terutama dipakai untuk menyerang Jokowi dan banyak diproduksi oleh akun@TrioMacan2000. Representasi yang dibangun diantaranya keterlibatan Jokowi dalam kasus korupsi bus Trans Jakarta dan korupsi yang dilakukan Jokowi saat menjabat sebagai walikota semarang. Dalam konstruksi wacana Jokowi korupsi ini juga muncul propaganda namacalling yang menyebut 'Jokowi pembohong' dan 'Jokowi tidak jujur'. Representasi negatif Jokowi tersebut dilemahkan akun@PartaiSocmed dengan representasi Prabowo berpolitik transaksional dan Prabowo didukung para koruptor. Koruptor yang dimaksud salah satunya Surya Dharma Ali yang ditangkap KPK menjelang pilpres setelah ditetapkan sebagai tersangka korupsi dana Haji. Pada pada saat itu Surya Dharma Ali merupakan Ketua Umum Partai Persatuan Pembangunan
(PPP) yang sempat diisukan akan mendampini Prabowo dalam pemilu presiden.

Kelima, representasi kepemimpinan calon presiden berkutat seputar definisi sosok calon presiden ideal yang tegas dan pembuat keputusan (decision maker). Wacana ini tidak muncul begitu saja namun memiliki konteks dimana Jokowi merupakan sosok yang sejak awal direpresentasikan sebagai calon presiden yang diatur oleh partai yang mengusungnya yakni Partai Demokrasi Indonesia Perjuangan (PDIP). Representasi tersebut terutama dibangun oleh@TrioMacan2000 bahkan sebelum Jokowi resmi dijadikan sebagai kandidat presiden oleh PDIP. Jokowi secara masif direpresentasikan sebagai 'capres boneka' dan di akhir menjelang pemilu disebut sebagai 'boneka asing' atau 'anthek asing' dan 'boneka militer'. Wacana ini di-counter oleh akun anonim pendukung Jokowi @ PartaiSocmed dengan representasi Prabowo penerus orba, dan prabowo boneka asing (Amerika) dan Prabowo ditolak oleh negara Asing (Australia).

Keenam, dalam merepresentasikan calon presiden ideal akun-akun Twitter anonim secara eksplisit juga menggunakan teknik propaganda 'fear' dengan memunculkan kembali ideologiideologi lama yang bertentangan dengan demokrasi seperti komunisme, fasisme, zionisme untuk merepresentasikan calon presiden tidak ideal. Jokowi secara keras direpresentasikan sebagai komunis terutama yang dibangun oleh@TrioMacan2000 yang dilegitimasi dengan penyebutan bahwa ayah Jokowi seorang komunis. Sementara@pkspiyungan merepresentasikan Jokowi komunis dengan alat legitimasi berupa peristiwa 'anarkis' pendukung Jokowi di Yogyakarta serta pernyataan rencana penghapusan kolom agama di Kartu Tanda Penduduk (KTP) yang dilontarkan oleh timses Jokowi prof Musdah Mulia.

Serangan 'Jokowi komunis' dilawan @ PartaiSocmed dibalas dengan merepresentasikan Prabowo sebagai zionis, penerus rezim orba dan pemimpin fasis. Sementara itu dalam mengkonstruksi calon presiden ideal, ketiga 
akun sama-sama menggunakan ideologi 'nasionalisme' untuk merepresentasikan calon presiden yang didukungnya. Baik Jokowi dan Prabowo sama-sama menggunakan simbol 'Bung Karno' sebagai sarana mengkonstruksi dirinya sebagai calon presiden nasionalis.

Ketujuh, isu kebijakan pengelolaan Sumber Daya Alam (SDA) menjadi salah satu isu utama yang dibawa para akun anonim. Dalam mengkonstruksi calon presiden tidak ideal kedua pihak sama-sama merepresentasikan capres lawan sebagai pemimpin yang memiliki kebijakan pengelolaan SDA yang pro-elite dalam hal ini konglomerat.

Masing-masing saling serang dengan menggunakan propaganda name calling yakni penggunaaan julukan negatif dimana Jokowi disebut sebagai 'anthek china', 'cukong cina' sementara Prabowo disebut sebagai capres yang didukung mafia migas. Perdebatan seputar pengelolaan SDA pro-konglomerat ini terutama melibatkan@partaiSocmed dengan@ TrioMacan2000.

Dalam perdebatan kedua akun anonim tersebut Prabowo direpresentasikan memiliki kedekatan dengan Riza Chalid pengusaha Migas era Orba, sementara Jokowi disebut memiliki kedekatan dengan konglomerat beretnis Cina, James Riady yang juga menjabat sebagai Wakil Ketua Lippo Groupyang juga anak dari Mochtar Riady pemilik Lippo Group.

Kedelapan, tampilan fisik calon presiden merupakan isu yang cukup dominan diperbincangkan oleh akun Twitter anonim. Pihak Jokowi melalui akun @PartaiSocmed merepresentasikan Jokowi sebagai calon presiden ideal yang dilekatkan dengan simbolsimbol Jenderal Soedirman yang kurus, pendiam (seperti Jokowi) namun memiliki karakter jujur dan tegas.

Dalam Twit terkait dengan hal itu@ PartaiSocmed sekaligus mengkontraskan dengan representasi Prabowo yang dilekatkan dengan simbol diktaktor Idi Amin dari Uganda yang berbadan besar yang diberi diskripsi sebagai pemimpin kejam, ambisius, brutal, labil dan grusa-grusu. Untuk melawan serangan akun anonim pendukung Jokowi, akun @pkspiyungan merepresentasikan Prabowo dengan kosa-kata jantan, ganteng, tegap dan kekar dan didukung visualisasi berupa foto Prabowo muda saat menjadi TNI. Sementara@TrioMacan2000 lebih berfokus pada serangan negatif terhadap fisik Jokowi dengan menggunakan kosa-kata seperti epilepsi, badut, jongos, klemer dan kurang gizi.

\section{Membongkar Identitas Akun Twitter Anonim}

Dalam konteks pemilu presiden 2014, belum ada pihak resmi yang mengungkap secara terbuka siapa orang-orang yang ada dibelakang akun anonim tersebut, dari mana mareka mendapatkan wacana-wacana yang diproduksi dan siapa sebenarnya mereka. Akun Twitter TrioMacan2000 mungkin menjadi salah satu akun yang telah didefinisikan pihak polisi sebagai akun 'berbayar' setelah para adminnya salah satunya bernama Raden Nuh dipenjara sejak 2015 karena terbukti melakukan pemerasan menggunakan akun@TrioMacan2000. Namun hal peristiwa tersebut tidak memberikan gambaran komprehensif mengenai peran akun Twitter anonim dalam proses demokrasi di Indonesia.

Penelitian ini ingin melengkapi berbagai pandangan tentang identitas akun Twitter anonim namun dengan menggunakan metode yang berbeda yakni dengan mengidentifikasi teks yang mereka produksi. Identitas yang dimaksud dalam penelitian ini bukanlah identitas nyata mereka seperti administrator, alamat kantor dan segala sesuatu yang menunjukkan fisik keberadaan mereka, namun lebih pada identitas yang terefleksi dari sikap politik, pola produksi wacana dan ideologi yang mereka bawa dalam perdebatan politik selama pemilu presiden 2014 . Dari data-data tersebut pula peneliti selanjutnya berharap bisa mengidentifikasi peran akun anonim dalam proses demokrasi di Indonesia.

\section{Kontestasi Akun Twitter Anonim: Panggung Perdebatan antar Elite}

Akun-akun Twiter anonim bukanlah 
akun yang membawa suara rakyat. Mereka sedang terlibat dalam kontestasi politik untuk kepentingan kelompok elite. Dalam konteks ini akun Twitter yang identik dengan medium suara rakyat dimanfaatkan dan dimanipulasi untuk kepentingan elite. Argumen peneliti ini didukung oleh tabel 2 yang memperlihatkan bahwa akun Twitter anonim yang menjadi sampel penelitian memiliki sikap politik yang terbelah menjadi dua dimana@Partaisocmed teridentifikasi mendukung Jokowi, sementara dua akun lain yakni@pkspiyungan dan @TrioMacan2000 mendukung Prabowo.

Fakta tersebut sekaligus bertentangan dengan profil akun anonim yang menyebut bahwa aktivitas mereka membawa kepentingan publik. Akun@PartaiSocmed menyebut dirinya sebagai akun yang mengusung konsep tidak memihak (objectivity), keadilan (fairness), keadilan untuk semua (justise for all), dan memberdayakan warga negara (empowering people).Akun@TrioMacan2000 dalam pilpres 2014 mendefinisikan profil mereka sebagai 'akun komunitas inteligen publik untuk pencerahan, pembasmi korupsi, kemunafikan penguasa negeri. Memprovokasi kejujuran anak bangsa yang cerdas dan merdeka'. Dua akun tersebut menggunakan jargon-jargon publik yang merepresentasikan mereka sebagai sesuatu yang sedang membawa suara rakyat dan dalam posisi membela kepentingan rakyat. Pada kenyataannya, keduanya ternyata terlibat dalam politik untuk kepentingan politik calon presiden yang mereka dukung. Jika diidentifikasi lebih lanjut, maka keberadaan akun Twitter anonim dalam konteks pemilu presiden 2014 ini bukan dalam usaha memperkuat kepentingan publik, namun justru menjadi alat politik. Padahal idealnya anonimitas merupakan salah satu alat yang bisa dipakai publik untuk menyuarakan kepentingan rakyat tanpa rasa takut (Zajácz, 2013; Chawki, 2006; Akdeniz, 2002).

\section{Akun Twitter Anonim: Sumber Wacana Irasional}

Proses perdebatan politik yang berlangsung antar akun anonim berlangsung secara irasional, meskipun data menunjukkan mereka juga menggunakan isu-isu rasional. Isu rasional yang dimaksud disini yakni isuisu yang memang menjadi kriteria seorang pemimpin yang demokratis, sebaliknya isu irasional didefinisikan sebagai isu yang tidak ada kaitannya dengan kriteria pemimpin demokratis. Berdasarkan studi empiris yang dilakukan oleh para peneliti (Hacker, 2004; Kinder et al., 1980; Miller, Wattenberg \& Malanchuk, 1986; Treneman \& McQuail, 1961 dalam Barisione, 2009) dalam setting negara demokrasi kriteria pemimpin politik biasanya dikaitkan dengan kompetensi, kekuatan, integritas, kemampuan dan kedekatan dengan rakyat.

Dalam penelitian ini isu rasional yang dikontestasikan tersebut diantaranya Hak Asasi Manusia, korupsi, kepemimpinan, Sumber Daya Manusia. Isu tersebut dilakukan dalam upaya menarik para pemilih yang memiliki pertimbangan memilih (voting behaviour) rasional. Sebagaimana disampaikan Minns (1984, dalam Adam \& Kingsley, 368) pemilih rasional mengevaluasi kriteria calon pemimpin terutama dengan melihat karakter dan prestasi kandidat, kemampuan memerintah dan kebijakan yang pro rakyat. Meskipun ada isu rasional dalam perbincangan yang dibangun oleh akunakun Twitter anonim pada dasarnya praktik komunikasi yang berlangsung didalamnya jauh dari nilai-nilai demokrasi. Argumen-argumen yang dibangun tidak mencerminkan prinsip transparansi dan akuntabilitas karena informasi yang dibawa akun-akun anonim tidak berangkat dari sumber yang kredibel. Diskusi politik yang terbentuk juga jauh dari nilai-nilai kepublikan sebagaimana disampaikan Habermas (1996; 303) terutama posisi yang sama (equal) dan komunikasi yang berorientasi pada konsensus. Pelanggaran prinsip kesetaraan atau yang oleh Habermas juga disebut sebagai komunikasi tanpa dominasi mengemuka dalam isu-isu irasional seperti dukungan kelompok agama yang memposisikan kelompok agama mayoritas semagai komunikator dominan, isu identitas 
yang terutama memarginalkan kelompok etnis minoritas Cina dan tampilan fisik calon presiden yang memproduksi ujaran kebencian (hates peech) berupa hasutan dengan cara menghina calon presiden baik Jokowi maupun Prabowo yang dilandaskan pada ketidak-idealan ciri fisik.

Sementara itu, isu irasional yang dibangun oleh akun Twitter anonim meliputi isu tentang dukungan kelompok agama, identitas calon presiden, penggunaan ideologi-ideologi yang kontra-demokrasi dan praktik ujaran kebencian dengan menggunakan tampilan fisik calon presiden. Isu irasional ini terutama dipakai dengan mekanisme propaganda yang menutup ruang diskusi kritis dan deliberatif sehingga melanggengkan komunikasi irasional. Diskusi berorientasi pada konflik dan bukan pada konsensus (Habermas, ibid) atau setidaknya berorientasi pada kompromi. Orientasi kepada konflik terutama muncul pada isu-isu sensitif agama dan etnis yang menghadirkan kembali pertentangan ideologi antar kelompok berbasis identitas di Indonesia. Twitter yang seharusnya memberikan ruang deliberatif justru difungsikan sebagai ruang penyemaian benih-benik konflik lama yang seharusnya telah hilang praktik demokrasi Indonesia di ruang nyata. Wacana berorientasi konflik ini disisi lain menjadi konsumsi pengguna Twitter yang didominasi oleh kelompok muda, sehingga pada akhirnya justru membahayakan persatuan dan kesatuan bangsa di masa kini dan masa depan.

\section{Akun Twitter Anonim sebagai Representasi Kekuasaan Elite}

Data analisis pada tabel 2 memperlihatkan bahwa perdebatan antar akun Twitter anonim menyiratkan adanya kekuasaan elite yang terlibat dalam produksi dan konsumsi wacana terutama ditemukan pada isu korupsi, isu pelanggaran HAM dan isu kebijakan pengelolaan Sumber Daya Alam. Kekuasaan elite yang dimaksud setidaknya dapat dilihat dari dua sudut pandang yakni elitisme komunikator dan elitisme isu; a) elitisme komunikator, dimana wacana ketiga isu tersebut merupakan perbincangan yang lebih melibatkan elite (KPK, Gub BI, Jaksa Agung Megawati), sementara publik tak memiliki kompetensi terkait dengan tema yang didiskusikan. Publik diposisikan sebagai audience pasif atau penonton saja, bahkan justru menjadi sasaran komunikasi yakni mobilisasi khalayak dan opini publik terhadap sosok masing-masing capres. Alur diskusi politik di Twitter dengan demikian bersifat tradisional atau one way communication bukan interaktif dan two way communication sebagaimana yang selama ini menjadi kekuatan media sosial; b) elitisme pesan, yakni penggunaan 3 isu (HAM, SDA dan korupsi) dengan sudut pandang yang tidak membumi karena hanya dimiliki, dikuasai, dan dipahami oleh kalangan elite. Kontestasi wacana Twitter anonim merupakan kontestasi antar elite yang dimunculkan secara terbuka di Twitter namun justru tidak mampu mencerahkan karena tidak adanya sarana konfirmasi kebenaran fakta.

Piliang $(2005 ; 328)$ menyebutnya kondisi demikian sebagai disinformasi komunikasi berwujud anarki komunikasi yang menyebabkan hilangnya ukuran-ukuran bersama dan etika komunikasi. Hal ini menyebabkan proses diskusi bukannya menghasilkan pemahaman bersama namun justru terjadi apa yang ia sebut sebagai keadaan sosial yang tidak akuntabel (social unaccountability). Ketiadaan etika oleh Piliang pada akhirnya menjadi sumber manipulasi, perekayasaan, pemalsuan dan penipuan realitas sebagaimana memang tercermin dalam politik imagologi di Twitter. Realitas yang telah tersamarkan dalam praktik imagologi diperburuk rendahnya akuntabilitas informasi yang bersumber problem anonimitas sumber. Pada akhirnya muncullah kebingungan di ruang publik politik. Komunikasi yang seharusnya menjernihkan permasalahan justu menjadi ajang produksi kebisingan (noise) yang menimbulkan kesimpang-siuran komunikasi. Noise ini disebut Piliang (ibid, 329) sebagai produk utama komunikasi kontemporer dimana didalamnya 'makna' merupakan sesuatu yang marginal.

Terkait dengan elitisme pesan, isu yang dimunculkan akun pseudonym (korupsi, 
kebijakan pengelolaan SDA dan pelanggaran hukum-HAM) merupakan tema diskusi kelompok ekslusif yang oleh Habermas (Hardiman, 2009: 146) disebut 'publik kuat'. Publik kuat didefinisikan sebagai sistem politik dimana aktor utamanya yakni para elite. Di seberangnya ada 'publik lemah' yakni ruang publik politis yang menjadi tempat warganegara membangun opini. 'Publik kuat' dalam hal ini menggunakan ketiga isu tersebut sebagai alat politik untuk mempengaruhi opini 'publik lemah' atas sosok capres 2014. Disinilah peneliti melihat adanya praktik dominasi diskusi politik oleh 'publik kuat' atas 'publik lemah'. 'Publik kuat' menggunakan pengetahuan (knowledge) mereka yang memadahi tentang isu elite untuk menguasai wacana publik lemah yang sebaliknya memiliki pemahaman yang tidak memadahi tentang ketiga isu tersebut. Minimnya pemahaman 'publik lemah' atas isu ini disebabkan karena terbatasnya atau bahkan tidak adanya akses 'publik lemah' untuk mengkonfirmasi validitas data yang bisa dipertanggun-jawabkan seperti yang disyaratkan dalam diskusi deliberatif. Hal ini membuka ruangruang manipulasi data yang membodohi 'publik lemah'. Sebagai contoh isu korupsi TransJakarta yang dipakai sebagai alat legitimasi representasi Jokowi koruptor bersifat elitis karena berbagai bukti dan argumen dipegang oleh 'publik kuat'. Demikian juga dengan isu pelanggaran hukum dan HAM, dimana 'publik lemah' atau khalayak sipil tidak pernah memiliki akses mengenai argumen-argumen rasional tentang terlibat atau tidaknya Prabowo.

\section{Simpulan}

Penelitian ini menemukan bahwa akun Twitter anonim telah dipakai untuk alat kontestasi politik antara pendukung Jokowi dan Prabowo. Akun anonim yang dalam konteks negara demokrasi seharusnya dimanfaatkan publik untuk alat kebebasan berekspresi tanpa rasa takut (Akdeniz, 2002; Chawki, 2006; Zajácz, 2013) justru dimanfaatkan sebagai medium bagi elite untuk sarana mencapai kekuasaan.
Bahkan perdebatan politik antara akun Twitter anonim justru menghadirkan kembali ideologi anti-demokrasi seperti komunisme, fasisme dan zionisme yang dikemas dalam propaganda fear untuk memunculkan ketakutan massa. Perdebatan politik juga bersifat elitis baik dari perspektif isu yang dibawa maupun komunikator yang dilibatkan yang memposisikan publik maya (netizen) hanya sebagai penonton perdebatan elite semata.

Dari sinilah penelitiberkesimpulan bahwa akun Twitter anonim dalam konteks perdebatan politik selama pemilu presiden 2014 tidak mendorong proses demokrasi namun menjadi patologi yang mendegradasi proses demokrasi. Dalam penelitian ini patologi demokrasi dipakai untuk menggambarkan malfungsi anonimitas akun Twitter yang seharusnya dapat dipakai sebagai sarana menyuarakan kebebasan berekspresi publik tanpa rasa takut namun justru dipakai untuk alat kepentingan kontestasi politik para elite.

Berdasarkan hasil temuan diatas, peneliti menawarkan beberapa saran, Pertama, urgensi kesadaran para aktor demokrasi ditingkat elite untuk membangun perdebatan politik yang transparan dan akuntabel dengan tidak melibatkan anonimitas untuk mencapai kekuasaan politik. Terbelahnya ideologi akun anonim dalam dua sikap politik membuktikan bahwa akun anonim tidak sedang dalam usaha membawa kepentingan publik namun sedang membawa kepentingan elite. Kedua, penelitian ini memberikan mengusulkan urgensi literasi media sosial terkait kemampuan netizen dalam membedakan anonimitas dalam media sosial yang dipakai sebagai alat demokrasi dengan anonimitas yang dipakai sebagai alat kekuasaan politik. Kemampuan tersebut selanjutnya memungkinkan netizen tidak reaktir terhadap berbagai wacana berorientasi konflik (salah satunya SARA) yang justru membahayakan pluralisme bangsa. Ketiga, meningkatkan daya kritis netizen dalam mengkonsumsi kontenkonten akun anonim terutama menjelang pemilu karena pada periode ini akun anonim rentan 
dipakai sebagai alat kampanye politik.

\section{Daftar Pustaka}

Akdeniz, Yaman. (2002). Anonymity, Democracy, and Cyberspace. Social Research, 69(1), 223-237 Barisione, Mauro. (2009). Valence Image and the Standardisation of Democratic Political Leadership. SAGE Publications 5(1), 4160 DOI: $10.1177 / 1742715008098309$ ht t p : / / 1 e a.s a g e p u b.com Fairclough, Norman. (1992). Discourse and Social Change. Cambridge: Polity Press Fairclough, Norman. (1989). Language and Power. New York: Longman Inc

Fairclough, Norman. (1995). Critical Discourse Analysis: The Critical Study of Language. New York: Longman Publishing Freeland, Felicia Hughes. (2007). Charisma and celebrity in Indonesian politics. Anthropological Theory. 7(2), 177-200

Gazali, Effendy.(2014), Learning by clicking: An experiment with social media democracyin Indonesia. International Communication Gazette. DOI: $10.1177 / 1748048514524119$ Habermas, J. (1996a) Between Facts and Norms: Contributions to a Discourse Theory of Law and Democracy. Cambridge: Polity Press. Hardiman, Budi.(2009b). Demokrasi Deliberatif: Menimbang 'Negara Hukum' dan ' Ruang Publik' dalam Teori Diskursus Jurgen Habermas. Yogyakarta: Kanisius

Irawanto, Philip \& Ryan. (2011). Tailoring Leadership Theory to Indonesian Culture. Global Business Review, 12(3), 355-366

Lim, Marlyna.(2013). Many Clicks but Little Sticks: Social Media Activism in Indonesia.JournalofContemporary Asia. DOI:10.1080/00472336.2013.769386

M. Chawki. (2006). Anonymity in Cyberspace: Finding the Balance between Privacy and Security. Droit-Tic, Juill.

Piliang, Yasraf A. (2005). Transpolitika: Dinamika PolitikdidalamEra Virtualitas.
Yogyakarta dan Bandung: Jalasutra Sari, Dewi Kartika \& Royke R. Siahainenia. (2015). Gerakan Sosial Baru di Ruang Publik Virtual pada Kasus Satinah. Jurnal Ilmu Komunikasi. 12 (1), 105-118 Syamsuddin, Din. (1993). Political Stability and Leadership Succession in Indonesia. Contemporary Southeast Asia, 15 (1), 12-23 Wadipalapa, Rendy Pahrun. Meme Culture \& Komedi-Satire Politik: Kontestasi Pemilihan Presiden dalam Media Baru (2015). Jurnal Ilmu Komunikasi. 12 (1), 1-18 Zajácz, Rita. (2013). WikiLeaks and the problem of anonymity: A network control perspective. Media, Culture \& Society, 35(4), 489-505 